
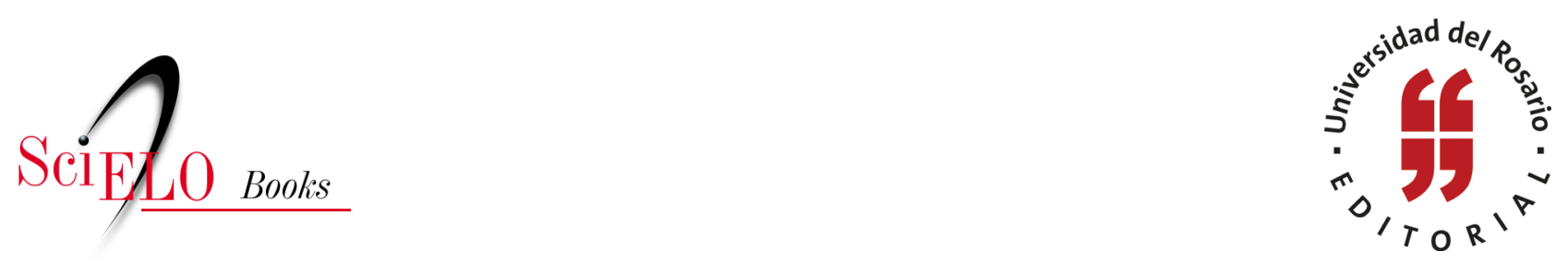

\title{
28. De Jair y, de paso, de mi tío Ed
}

\author{
César Augusto Tapias Hernández
}

TAPIAS HERNÁNDEZ, C.A. De Jair y, de paso, de mi tío Ed. In: Historias de familia: Etnografía delirante sobre el amor, la violencia y las drogas [online]. Bogotá: Editorial Universidad del Rosario, 2014, pp. 123-126. Textos de ciencias humanas collection. ISBN: 978-958-738-543-4.

https://doi.org/10.7476/9789587385434.0029.

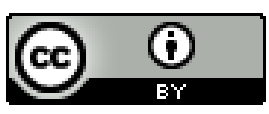

All the contents of this work, except where otherwise noted, is licensed under a Creative Commons Attribution 4.0 International license.

Todo o conteúdo deste trabalho, exceto quando houver ressalva, é publicado sob a licença Creative Commons Atribição 4.0.

Todo el contenido de esta obra, excepto donde se indique lo contrario, está bajo licencia de la licencia Creative Commons Reconocimento 4.0. 


\title{
28. De Jair y, de paso, de mi tío Ed
}

\author{
¿Que venga! ¿Que venga! El tiempo que nos prenda. Tuve tanta \\ paciencia. Que olvido siempre. \\ Arthur Rimbaud, Una temporada en el infierno
}

Hace algún tiempo tuve la oportunidad de conocer a Jair, alguien a quien el cine - la imagen que cuenta historias - le proporcionó una idea distinta del mundo posible en esta selva de hienas que es nuestra sociedad, según dice él mismo. Una película que contaba la historia de Gandhi le enseñó a Jair alternativas distintas a la de matar al enemigo. Hasta entonces, jamás había visto posible algo distinto al uso de la violencia cuando se tratara de la defensa, de la sobrevivencia... (Y, así mismo, en algún momento pensábamos algunos). Hace un par de meses, Jair estuvo de gira por Miami, Boston, Road Island y Washington con la fundación para la No Violencia de Martin Luther King, y luego con otro expillo del Doce, se fue por Europa: Fráncfort, Estocolmo... en el marco del Festival de la Unión Internacional de Juventudes Socialistas, una asociación internacional de jóvenes socialistas defensores de la democracia y la solidaridad.

Estoy seguro de que pocos pueden hacerse una idea de Jair. Yo lo puse aquí, en medio de estas historias, porque él ha tenido que ver con nuestra historia: la del tío Ed, la de mis primos JF y Camilo, la de Osorio y, por supuesto, la mía.

Jair es un man grandísimo, de contextura gruesa y habladito especial. Un grandulón que no teme decir a qué le teme y que se escabulle entre palabras para decir, a su estilo, lo que siente... Desde hace mucho tiempo ha sido un líder natural de su barrio, uno de esos que creen en la paz entre combos de pillos, porque ha sido de esos combos y sabe de la necesidad de parar la guerra que desangra las laderas de la ciudad... Pero, a pesar de eso, no está de todo contento el hombre, pues no falta el que entorpece los procesos. Mostrándome las fotos de sus viajes por Europa y Estados 
Unidos, me muestra Jair el recordatorio de Alexander, el parcerito que andaba con él pa' todas partes... ilo mataron! Y se muestra muy humano el Jair al reconocer sus flaquezas, debilidades de hombre callejero:

-En estos días vi a un pelao que le dio bala a Ramón el hermano mío, yo no sabía qué hacer... Le quería hacer el mandado; pero me vi hablando de paz para afuera y por dentro confrontándome... Finalmente, no pasó nada porque me fui; pero seguro que él baja por aquí y me siento tentado... Y yo sé que a la final uno le ha hecho mal a mucha gente y que no falta el que conspire contra uno, como con ganas de cobrárselas... Probándome más de uno me torea a ver si de pronto me cojo otra vez con ellos... Así es esta sociedad.

Desde que conozco a Jair, siempre hemos querido hacer una película, una donde sin mucha moraleja mostremos que no es para nada chimba ser el duro del barrio. Él, desde siempre, supo de mi gustico por el video y, a la final, sabe que el tema me suena: la sangre siempre llama, dice un vallenato... Y sé que hay mucho por decir tras las historias de los pillos que triunfan.

Cuando nos disponíamos a hablar del Ed, el menor de los Tales, llegó Wbeimar, hermano menor de Jair, y compañero de mi tío cuando estudiaban bachillerato. Ya le había dicho al grandulón de mis pretensiones, pero hablar de amigos muertos es duro; él se lo pensó mucho, yo no insistí al notar su silencio, de pronto dijo:

- ¿El Tales? ¡El Tales! El gordito estudió fue con Wbeimar, pero a la final nos hicimos buenos amigos y nos íbamos a gaminiar juntos... Creció y resultó estudiando con el Tino, y se hizo amigo del Tino... Un día el Tino nos prestó una pistola, una 25 ... como pa' salir a plaguiar por ahí. El Tales era bien... Lo recuerdo mucho, también al Osorio, ese que era su cuñado... Ed lo quería bastante. ¿Qué hubo de Ilsa y las niñas?... Y tus cuchos, ¿todavía están ahí?

A Jair siempre le ha parecido que mi casa es la de mis abuelos y siempre ha creído que ellos son mis padres, es decir, siempre me asoció como hermano de Ed, pero sabe que soy su sobrino... Y, aun así, cree que los demás sobrinos de él también lo son míos...

-Y tus sobrinos los policías ¿qué? Había uno en Apartadó, ¿sí o qué...?

Wbeimar, el hermano de Jair, es mecánico industrial. Sabe de su hermano, lógicamente, de sus vueltas en el barrio, y supo también cómo eran las del tío Ed. Incluso hoy se pregunta por qué uno resulta amigado del malo, del vicioso... del que da mal ejemplo:

- Ed venía en su cicla — cuenta Wbeimar- y nos íbamos a andar por todo El Pedregal y Castilla. Nuestras ciclas no tenían frenos, entonces manteníamos 
gastados los pisos. Un día no podía ir con él, porque ya no tenía con qué frenar, y él me dijo que fuéramos a la casa, y me regaló unas garritas. Entonces ahí sí nos fuimos a andar... y andar. Pasó el tiempo y cuando se compró la moto, la AX 100, me la traía y yo se la revisaba y tal... Me acuerdo mucho de las hermanas de él, y de la cucha. Se les notaba que lo querían mucho, y él bien loco como era.

—Y el chino que lo mató también murió — dice Jair- Siempre le dieron, pero se murió de una peritonitis el hijueputa ese... Era una gonorrea que mataba al que no le caía bien... Ese día el Tales vino y hablamos. Ya estaba muy periqueado, porque qué man pa' meter. Siempre me decía: "Metete, ome, mariquita”.

- Pero Ed camelló en fábricas Haceb — parece reivindicarlo WbeimarDespués se metió con las motos... y esos negocitos.

- Sí, yo lo conectaba con más de un man en el centro — se ufana Jair — . Y una vez vendió una con la que finalmente nos quedamos nosotros.

Y hubo también momentos de silencio en medio de los recuerdos. La evocación está cargada de silencios y suspiros. Por lo menos, yo me sollaba esos momentos viendo a Jair bien bacano, sentado, sin camisa, en pantaloneta, despreocupado de tombos y tanta vuel ta viendo las mismas noticias de todos los días. Hablaban de un loco que en Cartagena se montó en pelota sobre el caballo de Bolívar, queriendo cabalgar... Hasta pensé que era el poeta Gómez Jattin. Wbeimar comiendo, y la cuchita de ellos renarrando el cuento ese: un loco en pelota montando en el caballo de Bolívar... Y Jair, como siempre, atacado de repente por las ideas, como de repente resultaba hablando... Y el silencio desplazado:

- Me mantengo en mi posición contra el sistema carcelario de este país... Es que este es el único país donde a unos nos dan la cárcel por casa y a otros la casa por cárcel.

Y me reinstalo unos segundos antes, trasladándome, en una foto donde Jair luce los moretones de una fuga... En los tiempos de policías y de ladrones, correteando calle abajo...

- Te acordás, Tales, cuando me cayeron los tombos. Yo me les tiré de un cuarto piso. Ve lo que me hice ( señala Jair la foto) un morado en la pierna y no más...

El cuento de la no violencia sí que es interesante en un tipo así. Muchas veces, le manifesté a Jair mi alegría por lo que hacía y le pedí que no desistiera. Qué bacana la confrontación con uno mismo, y bacano cuando es uno el que gana...

—Yo me quiero ir pa' Bogotá, ome, Tales —insiste él_- Camellar en alguna cosa. Lo social ya no me gusta, ver morir a los amigos es muy duro; pero también he querido estudiar. El derecho me gusta mucho. La vuelta es que no he pasado a la de Antioquia, y pa' las otras no hay plata. Por lo de los viajes esos, conocí a una dura 
de la Bolivariana; pero que ellos dizque están muy mal de plata. Estoy esperando de pronto algo con monseñor como para entrar a la San Buenaventura... ¿Y vos sí te acordás de todo lo que hemos hablado, ome, Tales?

-Claro, parce... Así como me acuerdo de aquella vez que vimos juntos a Gandhi, la enésima vez que vos la veías.

Yo solo le dije eso, pero en el pensamiento tenía más para demostrarle el poder de mi memoria: recuerdo la cinta que vamos a hacer algún día: cómo vos recordás mi nombre y a mi abuela, a Ilsa y a las niñas...

Por la sala de la casa de Jair, salvando los obstáculos en que se vuelven los muebles, su pinta de unos seis o siete años corretea vendiendo corozos: "corozos a 50, corozos a 50....”.

Y yo me río y Jair apenas le dice:

-Hey, loquito ¿qué es lo que vendes?

...

—Tales, tráenos la historia que escribas... — puntualizó Wbeimar mientras me acompañaba a la puerta.

— ¿Claro, parcero! - le contesté-. Mañana mismo la traigo...

Y me fui a casa exorcizado...

Mi tío Ed murió disgustado conmigo. Me puse un día a decirle cosas que no eran mentiras; pero que el gordo no quería saber más... Así soy yo, hablando siempre demasiado. Recuerdo que solo él me preguntaba por mis películas. No sé cómo sabía de las convocatorias del Ministerio de la Cultura y me decía:

—Quiubo, ¿qué ha mandado?

-Y quería el Ed que me regresara a Cuba.

-Aquí todo es una mierda, y no falta el que se lo quiera lamber a uno y uno que no se deja, entonces es cuando hay tropel...

Sí, señor. Aparece la pelea y el bochinche... Como dicen en su salsa los de la orquesta Lebrón. De eso es de lo que Jair se aburre. La pelea y el bochinche... Eso nos dejó sin mi tío Ed.

A propósito de salsa, en la última farra que vivimos juntos, me reclamó por un disco que le dediqué borracho. Ya no encuentro una justificación válida, y creo que nunca se la di; pero a él también le gustaba el disco ese... en la voz de Ángel Canales:

—Que yo conozco a Perico Macoña / un mulato sin igual... Se mete un cigarro 'e los finos y enseguida empieza a desvariar... Ese mulato es un puente roto, nadie lo puede pasar, se para en las esquinas / y a todo el mundo empieza a insultar... tiene problemas... Ayyyy, con toditas sus amistades... tra la la la la la... 